\title{
Herlyn-Werner-Wunderlich syndrome: a case report
}

\author{
Sindrome de Herlyn-Werner-Wunderlich: relato de caso
}

\section{Case Report}

Keywords

Müllerian ducts/abnormalities

Hematocolpos

Vagina/abnormalities

Uterus/abnormalities

Kidney/abnormalities

Case reports

Palavras-chave

Ductos paramesonéfricos/anormalidades

Hematocolpia

Vagina/anormalidades

Útero/anormalidades

Rim/anormalidades

Relatos de casos

Correspondence

Pedro Salomao Piccinini

Department of Surgery

7703 Floyd Curl Drive

Mail Code 7840

San Antonio TX 78229-3900, USA

Received

07/01/2014

Accepted with modifications

02/20/2015

\section{Abstract}

Herlyn-Werner-Wunderlich (HWW) syndrome is a rare congenital disorder of the Müllerian ducts in which there is uterus didelphys, obstructed hemivagina and unilateral renal agenesis. The most common presentation is an abdominal mass secondary to hematocolpos, pain and dysmenorrhea. However, in some cases, such as the one we present here, menses are normal due to an obstructed hemivagina, and diagnosis can be delayed. We describe evaluation and surgical management of a 13 -year-old girl with this condition who was diagnosed by computed tomography (CT) scan and confirmed by pelvic ultrasound and surgical exploration, as well as a review of the literature.

\section{Resumo}

A síndrome de Herlyn-Werner-Wunderlich (HWW) é uma doença congênita rara dos dutos müllerianos, em que há útero didelfo, hemivagina obstruída e agenesia renal unilateral. A apresentação clínica mais comum é como uma massa abdominal secundária a hematocolpo, dor e dismenorreia. Em alguns casos, porém, como no que apresentamos aqui, a menstruação é normal devido à obstrução de uma hemivagina, e o diagnóstico pode ser tardio. Descrevemos neste trabalho a avaliação e manejo cirúrgico de uma paciente de 13 anos com essa condição que foi diagnosticada com uso de tomografia computadorizada e confirmada por ultrassonografia pélvica e exploração cirúrgica, bem como uma revisão da literatura. 


\section{Introduction}

Herlyn-Werner-Wunderlich (HWW) syndrome is a rare congenital disorder in which there is uterus didelphys, obstructed hemivagina and renal agenesis (lending its acronym, OHVIRA syndrome $)^{1-3}$. It is most commonly diagnosed in puberty due to pelvic and abdominal pain, but more rarely it can present in neonates or adults, with primary infertility, pyometra, urinary obstruction and ischiorectal swelling ${ }^{4,5}$. Due to its rarity, there is often a delay in diagnosis, both by primary care and emergency room physicians, which increases the risk of complications such as endometriosis and infertility ${ }^{6-9}$. The condition is most commonly diagnosed by imaging with ultrasound or computed tomography (CT) scan, although more recently magnetic resonance imaging (MRI) has emerged as the most sensitive diagnostic method. Treatment is carried out through excision of the vaginal septum, with good results; ultimately, around $80 \%$ of the patients are able to conceive. Therefore, it is important that physicians, who see patients with renal abnormalities, as well as those with endometriosis, maintain a high degree of suspicion for the condition, to guarantee a timely diagnosis and avoid complications from the syndrome.

\section{Case report}

A 13-year-old girl presented to the emergency room (ER) with a 5-month history of episodic perineal and rectal pain and abdominal fullness unrelated to eating. She had previously been seen at other emergency departments two and three months after the initial symptoms, but no imaging workup nor gynecological examinations were performed at the time. She was being treated for a presumptive diagnosis of proctalgia and constipation with tramadol, omeprazole, glycerin suppositories and enemas, with little relief. She denied any past medical or surgical history; menarche had occurred at age 11 , menses were every 30 days and lasted 5 days. No change in symptoms was noted to occur with menses. She was not sexually active and did not take contraceptive pills, hormonal therapy or other medications. Her development was normal otherwise. She was born at term of an uncomplicated pregnancy, and there was no family history of congenital disease.

On presentation, the patient was hemodynamically normal and afebrile, in no distress, with a large, palpable abdominal mass, which extended to the epigastric region, but with no peritoneal signs or hepatosplenomegaly. Laboratory exams were normal with a white blood cell count of 9.000 and a negative serum and urine beta HCG. CT scan of the abdomen and pelvis demonstrated a large 20x9x10 cm enlarged mass consistent with hydro/hematometrocolpos, an uterus didelphys, as well as absence of the left kidney (Figures 1 and 2). The condition was explained

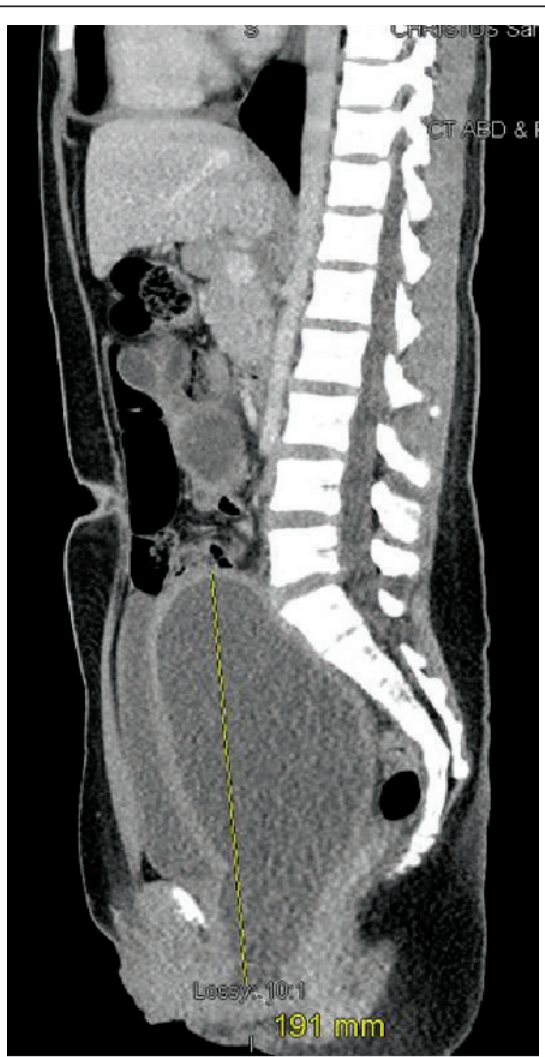

Figure 1. Sagittal computed tomography scan of abdomen and pelvis showing the enlarged uterus with fluid density compatible with hematocolpos measuring $191 \mathrm{~mm}$ in cranial-caudal length, with compression of the rectum and bladder.

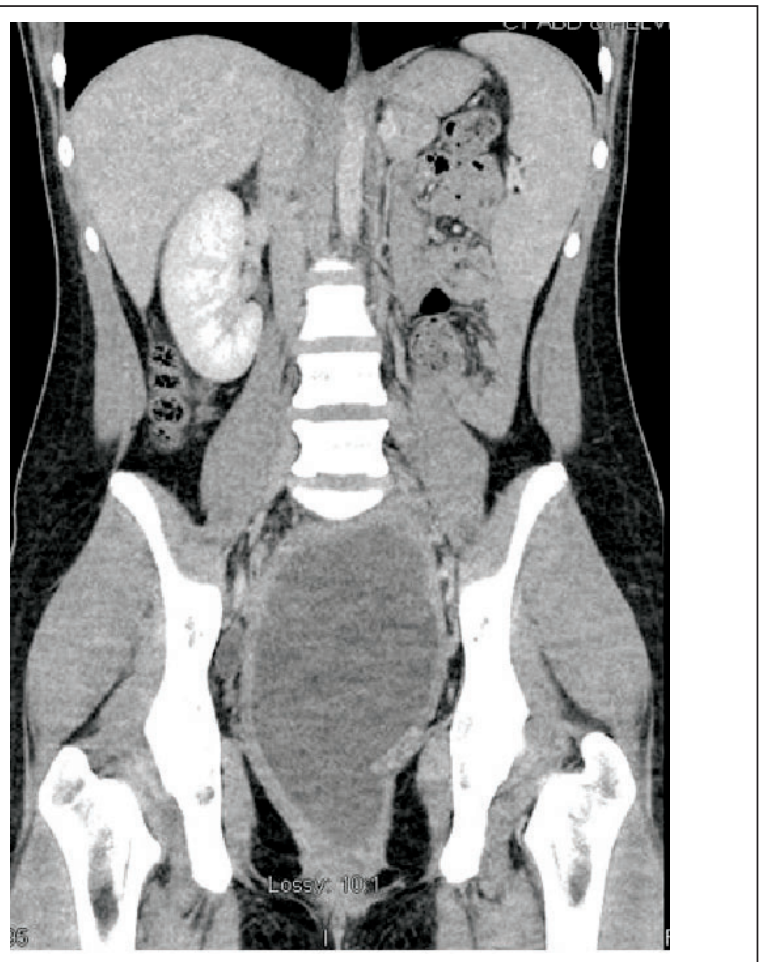

Figure 2. Coronal computed tomography scan of abdomen and pelvis demonstrating absence of the left kidney and enlarged uterus compatible with hematocolpos. 
to the family and patient, and the decision was made to perform a vaginal exam under anesthesia, eight hours after her presentation to the ER. The exam demonstrated an imperforate hymen and a very enlarged, bulging uterine cervix. On speculum exam, the right hemivagina was patent, while the left side ended blindly. We performed a hymenectomy and a longitudinal vaginal septotomy and $1.1 \mathrm{~L}$ of clotted blood was evacuated. There was no evidence of pyocolpos. The septum between the left and right hemivaginas was resected using electrocautery. A chromic gut suture was used to obtain hemostasis at the site of resection of the septum. Hysteroscopy was performed at the end. Visualization of the right cervical os was adequate, but the left cervical os could not be visualized secondary to edema of the left hemiuterus, which did not allow safe progression of the hysteroscope. The patient tolerated the procedure well, and was discharged home on the evening of surgery. On post-operative day 6 , the patient returned to the Emergency Department (ED) with a $39.1^{\circ} \mathrm{C}$ fever, nausea, vomiting and a $6 \times 6.1 \mathrm{~cm}$ left tubo-ovarian abscess, which was subsequently drained under ultrasound guidance. After seven days of intravenous ciprofloxacin and metronidazole, the patient was doing well and was discharged. At seven days and one-month follow-up, the patient had no complaints and had normal menstrual flow.

\section{Discussion}

Müllerian duct abnormalities cover a wide range of developmental anomalies, resulting from non-development, defective fusion, or defects in regression of the septum during fetal development. HWW syndrome is a rare disease in which there is the triad of uterus didelphys, obstructed hemivagina and renal agenesis (most often ipsilateral). It is classified as a type III Müllerian duct anomaly (MDA) associated with mesonephric duct anomalies and accounts for approximately 5\% of MDAs ${ }^{1-3,10}$. A case report was published as early as 1922 describing a female patient with unilateral hematocolpos, hematometria and hematosalpinx. However, the triad was not fully described until 1971.

In 1976, Wunderlich added bicornuate uterus as a feature of the syndrome. MDA result from non-development, defective fusion, or failure of resorption of the Müllerian (paramesonephric) ducts ${ }^{1}$, which originate most of the female genital tract, including the fallopian tubes, uterus, upper two-thirds of the vagina and the cervix. The upper two-thirds of the vagina derive independently of the Müllerian ducts, while the lower third derives from the urogenital sinus, therefore, vaginal abnormalities may or may not be found alongside uterine abnormalities ${ }^{6}$.

The estimated overall prevalence of MDA is $2-3 \%$ of women, although this number is higher in patients with reproductive disorders ${ }^{2,3,10}$. Uterus didelphys constitutes approximately $11 \%$ of MDAs; hypoplasia or agenesis of the uterus and proximal vagina constitute $5-10 \%$ of MDA. Associated renal anomalies are present in up to $43 \%$ of patients ${ }^{3,4}$. Approximately $75 \%$ of patients with didelphys uterus have a complete or partial vaginal septum ${ }^{5}$, which is most commonly longitudinal in HWW and is thought to reflect a disorder of lateral fusion between the inferior portions of the two Müllerian ducts ${ }^{6}$. Studies of uterine organogenesis have implicated the Hox and Wnt genes as regulators of uterine morphology, although specific gene mutations have not been identified nor associated with most $\mathrm{MDA}^{7}$.

The association of uterus didelphys with an obstructed hemivagina is explained by a defect in embryogenesis at the eighth week of gestation affecting the mesonephric and Müllerian ducts, in which there is non-fusion of Müllerian ducts or failed resorption of the uterine/vaginal septum ${ }^{1}$. Other defects which can be found include renal dysplasia, duplication of the kidneys and ureters ${ }^{11,12}$, ectopic ureter, as well as high-riding aortic bifurcation, IVC duplication, intestinal malrotation ${ }^{13}$ and ovarian malposition. Renal agenesis predicts an ipsilateral obstructive Müllerian duct abnormality $50 \%$ of the time and is ipsilateral to the dilated uterine cavity. The right side is affected nearly twice more frequently than the left one $^{3,4}$. In a case series of 70 patients, those with complete hemivaginal obstruction were significantly younger (12.86 years old) compared to those with incomplete obstruction (20.68 years); the most common symptom was dysmenorrhea in $64 \%$ of patients ${ }^{4,13}$.

The most common presentation is an abdominal mass secondary to hematocolpos from retained menstrual flow, pain and dysmenorrhea; presentation as acute pelvic or vaginal pain or as an acute abdomen is uncommon ${ }^{9,14}$. In incomplete obstruction, as in this patient, the diagnosis can be delayed as there is one hemivagina, which is patent, allowing for menstrual blood to exit, while the other side is obstructed; this eventually leads to a large hematocolpos ${ }^{11}$. The incidence varies between $0.1-3.8 \%$ in the literature ${ }^{4,15}$.

HWW is commonly diagnosed at the time of menarche. Rarely, the clotted blood may become infected, termed pyocolpos ${ }^{11}$, which can lead to pelvic inflammatory disease and tubo-ovarian abscess. Patients start to experience abdominal and, less commonly, perineal discomfort, secondary to the enlarging hematocolpos, which may also lead to urinary retention and constipation in some cases, typically 12-18 months after menarche. In cases of infected hematocolpos, fever, chills, nausea and vomiting may be present.

Early recognition is important in order to avoid complications such as retrograde tubal reflux and consequent endometriosis, as well as to preserve fertility ${ }^{4,16}$. 
Adenocarcinoma of the obstructed side of the uterine cervix and clear cell carcinoma of the obstructed portion of the vagina have also been described ${ }^{17}$. Delays in diagnosis are common due to a number of factors, especially in incomplete hemivaginal obstruction: as there is normal menstruation from the non-obstructed side, outflow obstruction is not suspected; the syndrome is also rare and thus it is not on the list of suspected diagnoses in most cases $^{16-18}$. Another reason is that in patients presenting with cyclical dysmenorrhea, the patient's primary care provider often prescribes non-steroidal anti-inflammatory drugs and oral contraceptives, which suppresses or eliminates menses and further delays recognition of the condition.

In cases of HWW, the vaginal septum is generally longitudinal and can have a variable thickness. Although CT scan was initially performed in this patient, transvaginal ultrasound has traditionally been the preferred initial imaging modality due to low cost, avoidance of radiation exposure and better imaging of the uterus and adnexa. Some authors now consider MRI as the gold standard for diagnosis and preoperative planning for treatment of $\mathrm{HWW}^{6,19-21}$, as it offers more detail with regard to uterine morphology, communication between vaginal and uterine lumens, and better evaluation of fluid contents $\mathrm{s}^{6,22,23}$. The association between HWW and endometriosis ${ }^{21,23,24}$ also favors MRI, as this is the superior imaging modality for endometriosis.

In adolescent girls, as a measure to post-pone surgery, $\mathrm{GnRH}$ analogues may be used to maintain amenorrhea $^{19}$, especially in cases of cervical atresia. Resection of the vaginal septum is the treatment of choice for obstructed hemivagina and resultant hematocolpos ${ }^{25-27}$; during surgery, preservation of the hymen is desirable in younger patients, although not always feasible. Vaginal septotomy is accomplished most commonly through a hysteroscopic approach ${ }^{28-30}$, although laparoscopic techniques have also been described. Laparoscopy adds the theoretical benefit of further delineating exact uterine anatomy prior to vaginal septotomy, although the effects on outcomes are yet to be evaluated. Patients who remain with stenosis of the vaginal septum after surgery can safely undergo re-resection of the septum with preserved ability to conceive and maintain pregnancy ${ }^{4}$. Either total or unilateral hysterectomy may be required in cases in which septal resection is not possible ${ }^{28}$ and may also be considered in patients with recurrent stenosis and severe endometrial/uterine infection or in patients who do not wish further pregnancies ${ }^{4}$.

Prognosis is good, with the major concern being preservation of fertility. Women with uterus didelphys have a high likelihood of becoming pregnant ${ }^{4,21,23,24}$, with approximately $80 \%$ of patients able to conceive ${ }^{31,32}$, but with elevated rates of premature delivery $(22 \%)$ and abortion (74\%); cesarean section is necessary in over $80 \%$ of patients ${ }^{32,33}$.

In summary, due to the rare and frequently asymptomatic nature of the HWW syndrome, gynecologists and other medical providers seeing patients diagnosed with renal agenesis should be aware of the possibility of associated uterine and vaginal abnormalities; conversely, in patients with uterine and vaginal abnormalities, workup for associated abnormalities, especially renal developmental defects, should be performed. Initial workup should include vaginal exam as well as transvaginal ultrasound or pelvic MRI. Referral to a gynecological or pediatric surgeon for vaginal septotomy should be prompt, in order to diminish the risk of endometriosis and infertility. Patients with the condition should be counseled about risks associated with the disease, including a higher likelihood of miscarriages ${ }^{33}$, although around $65 \%$ of patients will be able to carry pregnancy to term. Further research is needed to characterize risk factors for Müllerian duct defects in order to increase early detection and minimize morbidity from the condition ${ }^{6,8}$.

\section{References}

1. The American Fertility Society classifications of adnexal adhesions, distal tubal occlusion, tubal occlusion secondary to tubal ligation, tubal pregnancies, Müllerian anomalies and intrauterine adhesions. Fertil Steril. 1988;49(6):944-55.

2. Robbins JB, Broadwell C, Chow LC, Parry JP, Sadowski EA. Müllerian duct anomalies: embryological development, classification, and MRI assessment. J Magn Reson Imaging. 2015;41(1):1-12.

3. Vercellini P, Daguati R, Somigliana E, Vigano P, Lanzani A, Fedele L. Asymmetric lateral distribution of obstructed hemivagina and renal agenesis in women with uterus didelphys: institutional case series and a systematic literature review. Fertil Steril. 2007;87(4):719-24.

4. Orazi C, Lucchetti MC, Schingo PM, Marchetti P, Ferro F. HerlynWerner-Wunderlich syndrome: uterus didelphys, blind hemivagina and ipsilateral renal agenesis. Sonographic and MR findings in 11 cases. Pediatr Radiol. 2007;37(7):657-65.

5. Wang J, Zhu L, Lang J, Liu Z, Sun D, Leng J, et al. Clinical characteristics and treatment of Herlyn-Werner-Wunderlich syndrome. Arch Gynecol Obstet. 2014;290(5):947-50.

6. Epelman M, Dinan D, Gee MS, Servaes S, Lee EY, Darge $K$. Müllerian duct and related anomalies in children and adolescents. Magn Reson Imaging Clin N Am. 2013; $21(4): 773-89$.

7. Angthong W, Visetsripong M, Amornvithayachan $O$, Varavithya V. Herlyn-Werner-Wunderlich syndrome emphasizes ultrasonographic and MR findings: a case report and review of the literatures. J Med Assoc Thai. 2012;95(Suppl 12):S129-33. 
8. Spencer TE, Dunlap KA, Filant J. Comparative developmental biology of the uterus: insights into mechanisms and developmental disruption. Mol Cell Endocrinol. 2012;354(1-2):34-53.

9. Aydin R, Ozdemir AZ, Ozturk B, Bilgici MC, Tosun M. A rare cause of acute abdominal pain: Herlyn-Werner-Wunderlich syndrome. Pediatr Emerg Care. 2014;30(1):40-2.

10. Acién P. Incidence of Müllerian defects in fertile and infertile women. Hum Reprod. 1997; 12(7):1372-6.

11. Wozniakowska E, Torres A, Milart P, Wozniak S, Czuczwar P, Szkodziak P, et al. Delayed diagnosis of Herlyn-WernerWunderlich syndrome due to microperforation and pyocolpos in obstructed vaginal canal. J Pediatr Adolesc Gynecol. 2014;27(4):e79-81.

12. Zhou Y, Fu X, Qian H, Lin K, Wang J, Zhou S, et al. A Herlyn-WernerWunderlich syndrome variant with ipsilateral renal absence and a contralateral duplex collecting system in a 26-year-old female. Gynecol Obstet Invest. 2014;77(2):137-40.

13. Coskun A, Okur N, Ozdemir O, Kiran G, Arykan DC. Uterus didelphys with an obstructed unilateral vagina by a transverse vaginal septum associated with ipsilateral renal agenesis, duplication of inferior vena cava, high-riding aortic bifurcation, and intestinal malrotation: a case report. Fertil Steril. 2008;90(5):2006.e9-11.

14. Gungor Ugurlucan F, Bastu E, Gulsen G, Kurek Eken M, Akhan SE. OHVIRA syndrome presenting with acute abdomen: a case report and review of the literature. Clin Imaging. 2014;38(3):357-9

15. Ahmad Z, Goyal A, Das CJ, Deka D, Sharma R. Herlyn-WernerWunderlich syndrome presenting with infertility: Role of MRI in diagnosis. Indian J Radiol Imaging. 2013;23(3):243-6.

16. Kabiri D, Arzy Y, Hants Y. Herlyn-Werner-Wunderlich syndrome: uterus didelphys and obstructed hemivagina with unilateral renal agenesis. Isr Med Assoc J. 2013;15(1):66

17. Watanabe Y, Etoh T, Nakai H. Adenocarcinoma of the lower female genital tract in patients with Herlyn-Werner-Wunderlich syndrome. Am J Obstet Gynecol. 2012;207(6):e5-6.

18. Morino M, Hoshino M, Musha I. Obstructed hemivagina and ipsilateral renal agenesis with intestinal malrotation. Pediatr Int. 2013;55(4):e90-2.

19. Del Vescovo R, Battisti S, Di Paola V, Piccolo CL, Cazzato RL, Sansoni I, et al. Herlyn-Werner-Wunderlich syndrome: MRI findings, radiological guide (two cases and literature review), and differential diagnosis. BMC Med Imaging. 2012;12:4.
20. Aveiro AC, Miranda V, Cabral AJ, Nunes S, Paulo F, Freitas C. Herlyn-Werner-Wunderlich syndrome: a rare cause of pelvic pain in adolescent girls. BM Case Rep. 2011 ;2011:bcr0420114147.

21. Güdücü N, Gönenç $G$, Ișçi H, Yiğiter AB, Dünder I. Herlyn-WernerWunderlich syndrome-timely diagnosis is important to preserve fertility. J Pediatr Adolesc Gynecol. 2012;25(5):e 11 1-2.

22. Sen KK, Balasubramaniam D, Kanagaraj V. Magnetic resonance imaging in obstructive Müllerian anomalies. J Hum Reprod Sci. 2013;6(2):162-4.

23. Ahmad Z, Goyal A, Das JC, Deka D, Sharma R. Herlyn-WernerWunderlich syndrome presenting with infertility: role of MRI in diagnosis. Indian J Radiol Imaging. 2013;23(3):243-6.

24. Moshiri M, Seyal AR, Cruite I, Bhargava P. Herlyn-Werner-Wunderlich syndrome with a partially obstructed hemivagina. Radiol Case Rep. $2012 ; 7(4): 1-3$.

25. Kim TE, Lee GH, Choi YM, Jee BC, Ku SY, Suh CS, et al. Hysteroscopic resection of the vaginal septum in uterus didelphys with obstructed hemivagina: a case report. J Korean Med Sci. 2007;22(4):766-9.

26. Nassif J, Al Chami A, Abu Musa A, Nassar AH, Kurdi A, Ghulmiyyah L. Vaginoscopic resection of vaginal septum. Surg Technol Int. 2012;22:173-6.

27. Gholoum S, Puligandla PS, Hui T, Su W, Quiros E, Laberge JM. Management and outcome of patients with combined vaginal septum, bifid uterus, and ipsilateral renal agenesis (Herlyn-WernerWunderlich syndrome). J Pediatr Surg. 2006;41(5):987-92.

28. Beer WM, Carstairs SD. Herlyn Werner Wunderlich syndrome: an unusual presentation of acute vaginal pain. J Emerg Med. 2013;45(4):541-3.

29. Pereira N, Anderson SH, Verrecchio ES, Brown MA, Glassner M. Hemivaginal septum resection in a patient with a rare variant of Herlyn-Werner-Wunderlich syndrome. J Minim Invasive Gynecol. 2014;21(6): $1113-7$.

30. Xu B, Xue $M, X \cup D$. Hysteroscopic management of an oblique vaginal septum in a virgin girl with a rare variant of Herlyn-WernerWunderlich syndrome. J Minim Invasive Gynecol. 2015;22(1):7.

31. Heinonen PK. Clinical implications of the didelphic uterus: longterm follow-up of 49 cases. Eur J Obstet Gynecol Reprod Biol. 2000;91 (2): 183-90.

32. Sugiura-Ogasawara M, Ozaki Y, Suzumori N. Müllerian anomalies and recurrent miscarriage. Curr Opin Obstet Gynecol. $2013 ; 25(4): 293-8$

33. Tong J, Zhu L, Lang J. Clinical characteristics of 70 patients with Herlyn-Werner-Wunderlich syndrome. Int J Gynaecol Obstet. $2013 ; 121(2): 173-5$ 